\title{
A Comparison of Caudal Epidural with Intravenous Ketamine Anaesthesia in Below Umbilicus Surgery in Paediatric Patients
}

\author{
Geetanjali Singhal ${ }^{1}$, Manish Kumar Modi ${ }^{1}$, BL Mathur ${ }^{1}$ \\ ${ }^{1}$ Department of Anaesthesiology, JNU Medical College, Jaipur, India.
}

\section{Abstract}

Background: Caudal epidural block has been found to be a safe and simple technique in paediatric surgery below umbilicus. This study was done to make a clinical comparison between effectiveness of caudal epidural and general anaesthesia with total intravenous Ketamine, in terms of intra-op and post- op analgesia. Subjects and Methods: Fifty patients in age group 1-12 years undergoing surgery below umbilicus were divided into 2 groups .Each group had 25 patients belonging to ASA groups 1 and 2. Group A was given general anaesthesia with total intravenous Ketamine. Group B received Caudal Epidural block under brief general anaesthesia with thiopentone. Results: Caudal block using injection $1 \%$ xylocaine was found to be a valuable technique of anaesthesia in paediatric surgery below umbilicus as it offered greater advantage of post op analgesia up to 6 hours. The recovery of consciousness was rapid on account of light general anaesthesia. Conclusion: Caudal blocks are effective in alleviating pain during intra op and post op period in sub-umbilical surgeries in paediatric patients. They offer perioperative hemodynamic stability along with the added advantage of minimal post-op side effects.

Keywords: Caudal epidural, ketamine, postop analgesia.

Corresponding Author: Dr. Manish Kumar Modi, F- 9a, C block, Mahesh Nagar, Jaipur-302015, Rajasthan, India.

Received: September 2019

Accepted: September 2019

\section{Introduction}

Infants and children are ideal subjects for caudal epidural anaesthesia. This procedure is simple, safe and the patient is remarkably comfortable in the post op period. Caudal block is appropriate for sub umbilical surgeries including urologic or orthopedic surgical procedures. ${ }^{[1]}$ Minor out- patient surgeries too are very well suited to single shot caudal block. The patient leaves the hospital in a comfortable and cooperative state and the lingering post-op analgesia is of additional benefit. ${ }^{[2]}$ Ketamine is a popular drug in paediatric surgery as it gives complete anaesthesia with analgesia, at the same time preserving the vital functions of brain stem. However, despite this fact Ketamine may not be the ideal anaesthetic agent. One of the commonest sequelae of intravenous ketamine is emergence delirium. ${ }^{[3]}$ The purpose of this study was to compare analgesic efficacy of Caudal Anaesthesia with Total intravenous Ketamine.

\section{Subjects and Methods}

The present study was conducted in JNU Hospital, Jaipur .It was a hospital based prospective randomized interventional comparative study. 50 patients of age group 1-12 years and falling into ASA categories 1 and 2, were divided into two groups. Each group had 25 patients and were to undergo sub umbilical surgery. The patients were randomly designated into two groups, A and B. Simple randomization by using computer generated random number- table was done. Allocations were concealed by serially numbered opaque sealed envelopes (SNOSE) technique. These envelopes were opened prior to surgery.

\section{Exclusion criteria}

Patients with history or evidence of local sepsis, drug hypersensitivity, history of coagulopathy, or delayed milestones. Patients with pre-existing neurological or spinal diseases were also excluded from the study.

During pre-anaesthetic check-up all parents were explained about the procedure and written informed consent was taken. Before commencing surgery heart rate, blood pressure, ECG and $\mathrm{SpO} 2$ were noted.

Group A: was given General Anaesthesia with total intravenous ketamine with ketamine $1 \%$ in the dose of $2 \mathrm{mg} / \mathrm{kg}$. Subsequently incremental doses of ketamine were given intravenously as and when required. ${ }^{[4]}$ The time of induction was noted.

Group B: To keep the patients still brief general anaesthesia was given with inj. Thiopentone $1 \%(4-5 \mathrm{mg} / \mathrm{kg})$ i.v. The child was positioned for caudal block in lateral decubitus position with knees flexed. Sacral region was prepared with betadine. Sacral hiatus was identified and with all aseptic precautions a 25 gauge hypodermic needle was inserted at a point in the midline and pushed cephalad by $1-2 \mathrm{~cm}$ into sacral canal. $^{[5-7]} 1 \%$ xylocaine $(0.5-1.25 \mathrm{ml} / \mathrm{kg})$ was injected after negative aspiration test for blood and CSF. The time of caudal epidural was recorded. Surgery commenced $10 \mathrm{~min}$ 
after caudal injection after ensuring complete analgesia.

No other medications were used during surgery. Intraoperative monitoring of vitals was continued. Heart rate and blood pressure were recorded before induction, after induction and every $10 \mathrm{~min}$ till the completion of surgery.

The monitoring was continued post operatively. The main parameter measured was the duration of post op analgesia. This was measured as the time period between the completion of surgery until the time the FLACC SCORE (face, legs, activity, cry, consolability score) reached $>4$ in children below 7 yrs. ${ }^{[8]}$ In children above 7 years VAS Scale (visual analogue scale) was used and the time period between completion of surgery until the time the VAS score was 3 or more was noted and analgesia was provided with paracetamol rectal suppository $15 \mathrm{mg} / \mathrm{kg}$.

Secondary outcomes were recovery period and post op side effects. Recovery period was assessed using Ramsay sedation scale. It was measured from time of finishing surgery till when Ramsay Sedation Score was 2 or less and was noted at 15 minute interval after finishing surgery. ${ }^{[9]}$

Postop side effects were noted for 24 hrs and managed. Postoperative respiratory depression was defined as respiratory rate $<10 /$ min or decrease in $\mathrm{SpO} 2<95 \%$. A more than $20 \%$ drop in BP and heart rate from pre-op values was defined as hypotension or bradycardia respectively and was managed appropriately. Side-effects such as breath-holding, apnoea, hypotension, involuntary movements, nausea and vomiting, nystagmus, emergence phenomenon, opisthotonus etc. were noted.

Any increase in HR or mean arterial pressure (MAP) more than $20 \%$ of the pre- incision values was considered as failed caudal block. There was no incidence of failed caudal block in any patient.

\section{Statistical Analysis}

Data was entered and analysed using an open source software, $\mathrm{R}$ version 3.5.1. Qantitative data was expressed as mean \pm standard deviation and qualitative data was expressed in terms of frequency and percentage. The hypothesis testing of the quantitative data was conducted using Student's t-test. $\mathrm{P}$ value less than $<0.05$ was considered as stastically significant.

\section{Results}

\section{Age Distribution}

Table 1: Distribution of patients between two groups according to age

\begin{tabular}{|l|l|l|l|l|}
\hline \multirow{2}{*}{$\begin{array}{l}\text { Age Group } \\
\text { (In Years) }\end{array}$} & \multicolumn{2}{|l|}{ Ketamine Group } & \multicolumn{2}{l|}{ Caudal Group } \\
\cline { 2 - 5 } & Count & \% & Count & \% \\
\hline $1-3$ & 8 & $32 \%$ & 15 & $60 \%$ \\
\hline$>3-6$ & 7 & $28 \%$ & 6 & $24 \%$ \\
\hline$>6-9$ & 4 & $16 \%$ & 1 & $4 \%$ \\
\hline$>9-12$ & 6 & $24 \%$ & 3 & $12 \%$ \\
\hline Total & 25 & $100 \%$ & 25 & $100 \%$ \\
\hline
\end{tabular}

Both the groups were comparable regarding demographic parameters including age. [Table 1]

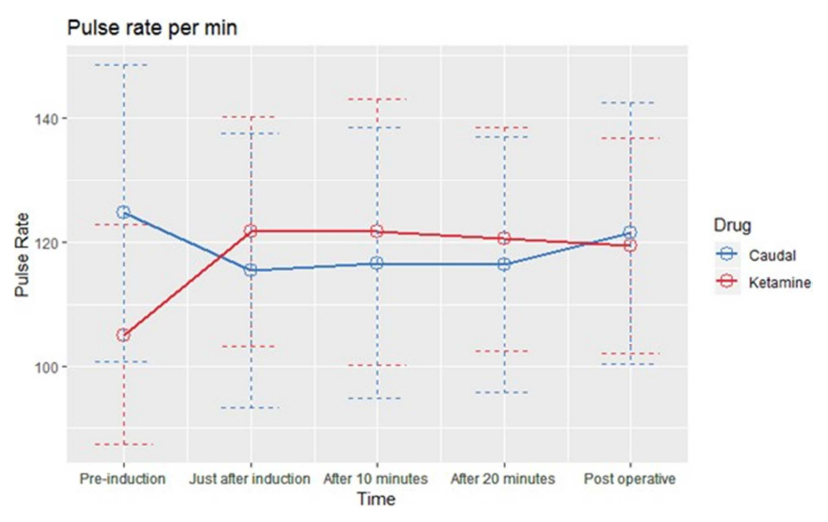

$\mathbf{p}=\mathbf{n s}$

Figure 1: Comparision of heart rate between the two groups

It was observed that there was a rising trend in the heart rate in Ketamine group after induction to immediate post op period from $105.12+17.65$ to $119.44+17.39$ [Figure 1]. In Caudal group the mean heart rate showed a decreasing trend after induction to immediate post op period from 124.64+ 23.88 to $121.44+21.11$. Our statistical analysis showed that the difference in heart rate between the two groups was not of statistical significance as the $\mathrm{p}$ value was $>0.05$.

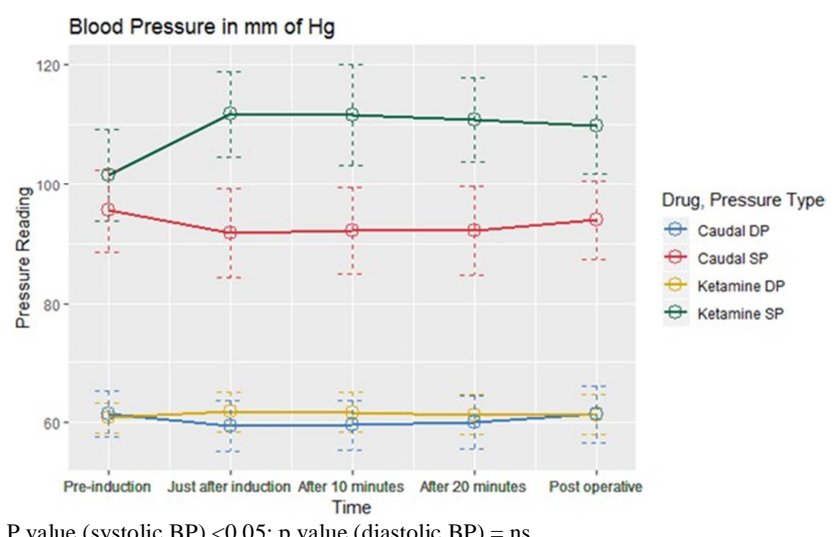

Figure 2: Comparision of systolic and diastolic blood pressure between the two groups

\section{Recovery Period}

Table 2: Comparision of recovery period between the two groups

\begin{tabular}{|l|l|l|l|l|}
\hline \multirow{3}{*}{ Time(Mins) } & \multicolumn{3}{l}{ Recovery period } & \multicolumn{2}{l|}{ Caudal } \\
\cline { 2 - 5 } & Ketamine & Nos. & $\%$ \\
\cline { 2 - 5 } & Nos. & $\%$ & 25.00 & 100.00 \\
\hline $0-15$ & - & - & - & - \\
\hline $16-13$ & - & - & - & - \\
\hline $31-45$ & 2.00 & 8.00 & - & - \\
\hline $46-60$ & 6.00 & 24.00 & - & - \\
\hline $61-75$ & 2.00 & 8.00 & - & - \\
\hline $76-90$ & 6.00 & 24.00 & - & - \\
\hline $91-105$ & - & - & - & - \\
\hline $106-120$ & 6.00 & 24.00 & - & - \\
\hline$>121$ & 3.00 & 12.00 & - & 100.00 \\
\hline Total & 25.00 & 100.00 & 25.00 & \\
\hline
\end{tabular}

Systolic blood pressure in Ketamine group showed increasing trend from pre-induction to immediate post-op period whereas the caudal group showed decreasing trend. 
However the diastolic blood pressure in the two studies. The groups did not show much variation. The difference between systolic blood pressures of two groups was statistically significant as $p$ value was $<0.05$. [Figure 2]

The study showed that the recovery period noted from completion of surgery in caudal group patients was very rapid and ranged from 0-15 minutes as compared to ketamine which varied from 30 min to $>120$ minutes depending on the last top- up dose. [Table 2]

\section{Post Op Analgesia}

Table 3: Comparision of post-op analgesia between the two groups

\begin{tabular}{|l|l|l|l|l|}
\hline \multirow{3}{*}{ Time(Hrs) } & \multicolumn{4}{l}{ Post op analgesia } \\
\cline { 2 - 5 } & Ketamine & Caudal & \multicolumn{2}{l|}{} \\
\cline { 2 - 5 } & Nos. & $\%$ & Nos. & \% \\
\hline Nil & - & - & - & - \\
\hline$<1$ & 4.00 & 16.00 & - & - \\
\hline $1-2$ & 12.00 & 48.00 & - & - \\
\hline $2-3$ & 6.00 & 24.00 & 3.00 & 12.00 \\
\hline $3-4$ & 3.00 & 12.00 & 8.00 & 32.00 \\
\hline $4-5$ & - & - & 7.00 & 28.00 \\
\hline $5-6$ & - & - & 5.00 & 20.00 \\
\hline$>6$ & - & - & 2.00 & 8.00 \\
\hline Total & 25.00 & 100.00 & 25.00 & 100.00 \\
\hline
\end{tabular}

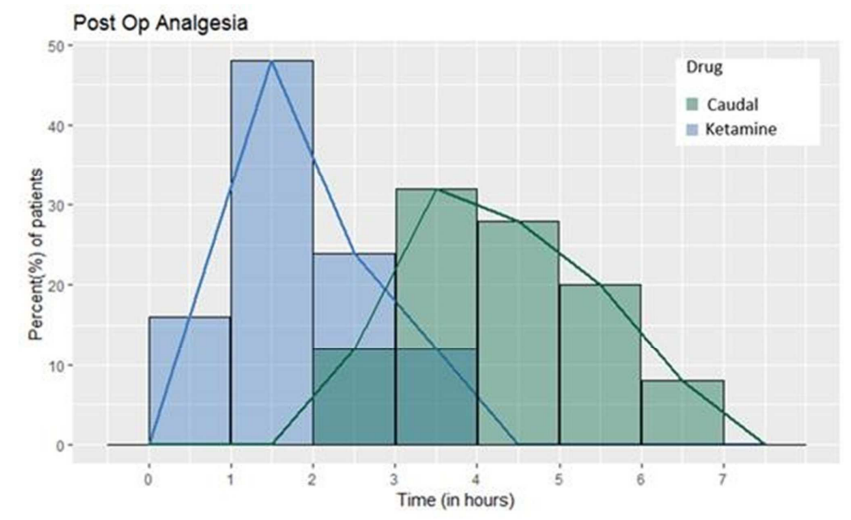

Figure 3: Post Op Analgesia.

In Caudal group all patients showed post op analgesia more than 2 hours, and extended upto 7 hours in some patients. In ketamine group maximum number of patients showed post op analgesia between 1-2 hours. (As shown in the graph in [Figure 3])

\section{Post OP Side Effects}

Table 4: Comparision of post-op side effects between the two groups

\begin{tabular}{|l|l|l|l|l|}
\hline \multirow{2}{*}{ Side effects } & \multicolumn{3}{|l|}{ Post op Side effects } \\
\cline { 2 - 5 } & Ketamine & Caudal & \multicolumn{2}{l|}{} \\
\cline { 2 - 5 } & Nos. & $\%$ & Nos. & $\%$ \\
\hline Airway Obstruction & 4.00 & 16.00 & - & - \\
\hline Vomiting & 3.00 & 12.00 & 1.00 & 4.00 \\
\hline Resp depression & 3.00 & 12.00 & - & - \\
\hline Laryngospasm & - & - & - & - \\
\hline Rigors & - & - & - & - \\
\hline $\begin{array}{l}\text { Emergence } \\
\text { Phenomenon }\end{array}$ & 10 & 40 & - & - \\
\hline
\end{tabular}

In Caudal group only 1 patient had vomiting in the post op period. In Ketamine group $80 \%$ patients showed post op side effects like airway obstruction, respiratory depression, vomiting and emergence phenomenon. [Table 4]

\section{Discussion}

Caudal epidural has been extensively used in paediatric patients for surgeries below umbilicus. Ketamine too has been widely used in paediatric procedures. However, a comprehensive research of literature revealed that a comparative study between these two techniques has never been made. Hence this study was planned to evaluate analgesic quality, recovery of consciousness and post-op side effects between the two methods of anaesthesia. The present study was undertaken to compare caudal block anaesthesia and total i.v. ketamine anaesthesia in a subset of pediatric patients undergoing below umbilicus surgery. Caudal block was performed under brief G.A. with $1 \%$ thiopentone.

Various studies have shown that children are technically ideally suited for caudal analgesia as the sacral hiatus is easily felt and puncture is easily done with a small needle. ${ }^{[10]}$ The phencyclidine derivative ketamine has been described as an ideal agent for paediatric sedation. Ketamine induced dissociation causes analgesia with preservation of respiratory and cardiovascular functions along with profound amnesia. ${ }^{[4]}$ In this study, we found that caudal epidural is a very useful technique in paediatric patients undergoing surgeries below umbilicus. The post- op analgesia was extremely significant in caudal group thereby considerably minimizing the need for rescue analgesics in the postop period. It was more than 2 hours in all the patients of caudal group. In maximum number of patients the duration of analgesia was between 3-6 hours [Table 2, Figure 3]. This greatly minimized the use of post op analgesics in children. The analgesia in caudal has been attributed to the interruption of somatic pain pathway. Caudal Analgesia is now firmly established in pediatric practice. Our trial is comparable with a study that proved that caudal epidural offers a combination of excellent pain relief along with minimal side-effects, thus providing high patient comfort as compared to other modes of analgesia. ${ }^{[1]}$ In ketamine group the duration of post op analgesia was found to be between 1-2 hours in maximum number of patients. This considerably increased the requirement of post op analgesics.

The recovery to consciousness (Ramsay Sedation Score 2) was very rapid in patients with caudal block and was comparable with other studies. ${ }^{[12]}$ It varied between 0-15 min in all the patients of caudal group. The patients woke up to sedation score 2 with light stimulus. The recovery period in ketamine group varied from $30 \mathrm{~min}$ to $>120$ minutes depending on the last top up dose [Table 1].

It was found in our study that in ketamine group, there was a rise in heart rate from $105.12+17.65$ (pre-induction)to $121.76+18.53$ (just after induction) accompanied with a rise in systolic and diastolic blood pressure from 101.52 $+7.72 / 60.80+2.53 \mathrm{~mm} \mathrm{Hg}$ (pre induction) to $111.68+$ $7.08 / 61.84+3.29 \mathrm{~mm} \mathrm{Hg}$ just after induction [Figure 1,2]. The rise was maintained up till the post op period. This rise of heart rate and blood pressure has been attributed to central stimulation by Ketamine producing an overall sympathetic response with a concomitant vagal inhibition. ${ }^{[13-15]}$ In 
contrast, in Caudal group there was fall in heart rate from $124.64+23.88$ (Pre-induction) to $115.44+22.08$ after induction. This was accompanied by a slight decrease in Blood pressure soon after induction in patients with caudal block. However, in the studies conducted by Larouse (2002), no significant modification in heart rate was found by Caudal Anaesthesia. ${ }^{[16,17]}$

Post op side effects were minimal in caudal group (4.1\%) and mainly manifested as post op vomiting. In ketamine group $80 \%$ patients showed post op side-effects in the form of emergence delirium, airway obstruction, vomiting, and respiratory depression [Table 3]. Here our findings were comparable with MC Howes (2004) who quoted several post op side effects with Ketamine in pediatric patients in the form of vomiting, laryngospasm, apnoea, emergence phenomenon, nystagmus, opisthotonus etc. Therefore, Caudal epidural was found to be a safer technique as such side-effects were a rare occurrence and respiratory rate, oxygen saturation were well maintained. Therefore it was found in our study that caudal block offered a greater advantage in paediatric age group which is particularly more prone to respiratory side effects.

\section{Conclusion}

It was concluded in this study that caudal block is a valuable technique of anaesthesia in pediatric surgery below umbilicus as post- op analgesia was considerably prolonged, thereby minimizing the need of rescue analgesics in the post op period. The recovery of consciousness is rapid on account of brief general anaesthesia. Post op side effects are minimal as compared to Ketamine anaesthesia.

\section{Acknowledgements}

The authors would like to thank Ms Kaveri Singhal, Data scientist for her valuable support in analyzing the data.

\section{References}

1. Raux O, Dadure C, Carr J, Rochette A. Paediatric caudal anaesthesia. Update in Anaesthesia. 2010;26: 32-36.

2. Tsui BC, Berde CB. Caudal analgesia and anaesthesia techniques in children. Op. Curr Anaesthesiology. 2005; 18: 283-8.

3. Howes,MC. Ketamine for pediatric sedation/analgesia in emergency department. Emerg. Med. J. 2004; 21: 275- 80.

4. Dach RJ,Innes GM,.Intravenous Ketamine sedation in paediatric patients in emergency department. Ann. Emerg.Med.1997; 29: 146-50.

5. Aggarwal A, Aggarwal A, Harjeet, Sahni D. Morphometry of sacral hiatus and its clinical relevance in caudal epidural block. Surg. Radiol. Anat.2009;31(10):793-800.

6. Wiegele M,Marhofer P, Lonneqvist P. Caudal epidural blocks in paediatric patients:a review and practical considerations.BJA. 2019; 122(4): 509-517.

7. Brull R, Macfarlane AJR, Chan VWS. Spinal, epidural and caudal anaesthesia. In: Miller R.D., editor.Millers Anaesthesia ,Elsevier Health Sciences; 2015.pp.1684-1720

8. Merkel SI, Voepel-Lewis T, Shayevitz JR, Malviya S. The FLACC-A behavioural scale for scoring post op pain in young children. Pediatr Nurs. 1997;23:293-7.

9. Ramsay MA, Luterman DL. Dexmedetomidine as a total intravenous anaesthetic agent. Anaesthesiology. 2004;101:787-90.

10. Senoglu N, Senoglu M, Oksuz H et al. Landmarks of sacral hiatus for caudal epidural block: an anatomical study. BJA.2005; 95(5): 692-5

11. Patel D. Epidural analgesia for children. Continuing Education in Anaesthesia, critical care and pain.2006; 6(2):63-66.

12. Doda M, Sambrita M. Postoperative analgesia in children - comparative study below caudal bupivacaine and bupivacaine plus tramadol. I.J.A;2009; 53(4):463-66.

13. Larousse E,Asehnoune K,Dartayet B et al.The haemodynamic effect of paediatric caudal anaesthesia assessed by esophageal Doppler.Anaesth .Analg.May 2002;94(5):1165-1168

14. Liebe T,Shijia Li,Walter $\mathrm{M}$. Factors influencing cardiovascular response to sub- anaesthetic Ketamine- a randomized controlled trial . Neuropharmacology. 2017;Nov 20 (11):909-918.

15. Suleiman ZA,Kolawole IK,Bolaji BU. Evaluation of cardiovascular stimulation effects after induction with Ketamine, J West Afr Coll Surg.2012; Jan-Mar 2(1):38-52.

16. Bromage PR, Philip R. Epidural analgesia. 1978; firstedition, 258 and264.

17. Deng M, Wang X, Wang L, Zheng S. Hemodynamic effects of newborn caudal anaesthesia assessed by transthoracic echocardiography: a randomized, double blind controlled study. Paediatr Anaesth. 2008; 18: $1075-81$

Copyright: ( ) the author(s), publisher. Academia Anesthesiologica International is an Official Publication of "Society for Health Care \& Research Development". It is an open-access article distributed under the terms of the Creative Commons Attribution Non-Commercial License, which permits unrestricted non-commercial use, distribution, and reproduction in any medium, provided the original work is properly cited.

How to cite this article: Singhal G, Modi MK, Mathur BL. A Comparison of Caudal Epidural with Intravenous Ketamine Anaesthesia in Below Umbilicus Surgery in Paediatric Patients. Acad. Anesthesiol. Int. 2019;4(2):197-200.

DOI: dx.doi.org/10.21276/aan.2019.4.2.45

Source of Support: Nil, Conflict of Interest: None declared. 